Volumen 19 n 42016

\title{
Editorial
}

\section{Algunas reflexiones sobre "la Bolsa Única" de contratación del Sistema Andaluz de Salud y las Áreas Específicas}

A estas alturas, no quiero abundar más en la necesidad de una especialización para enfermería nefrológica, asunto que se ha tratado ya en esta editorial años atrás.

Lo más curioso de todo, es que la especialización de enfermería en algunas áreas asistenciales concretas, no es una necesidad de los profesionales, sino de los pacientes. Es decir, la Especialidad de Matrona no se creó para satisfacer a un grupo de profesionales de enfermería que tenían esa aspiración, se crea para atender una necesidad sanitaria muy concreta de una parte de la población. ¿Tan difícil de entender es esto por parte de los responsables de la sanidad en este país?

Sin embargo, aunque no se ha querido reconocer esta necesidad de "especialización" de enfermería, se reconoce implícitamente la necesidad de tener "experiencia previa" para trabajar en algunas áreas asistenciales "específicas". En varias Comunidades Autónomas (CCAA) se llegó a acuerdos con los agentes sociales para el reconocimiento de perfiles profesionales en las bolsas de contratación temporales para enfermería, entendiendo como tales "las áreas específicas de Enfermería que se utilizan para la cobertura de ciertos servicios concretos donde, debido a su complejidad o especificidad, es recomendable que el enfermero sustituto cuente con un mínimo de experiencia y/o conocimientos específicos relacionados con el área en cuestión". De hecho, en una revisión de la situación de la contratación de enfermeras por perfiles, como consecuencia de acuerdos con sindicatos, encontramos que en 13 CCAA contemplan esta posibilidad; y que el área específica de diálisis o hemodiálisis, se contempla en 12 de ellas ${ }^{1}$, aunque el área específica aceptada como diferenciada de la generalista es diálisis o hemodiálisis, no enfermería nefrológica. En un plano estrictamente laboral y desde el punto de vista de la seguridad de los pacientes, esta posibilidad de contratación resuelve en parte la carencia de enfermeras/os formados en un área tan especializada como la diálisis. Sin embargo, no ha solucionado el problema estructural del personal con plaza fija, donde lo que prima es la antigüedad en el sistema sanitario y no sus competencias profesionales.

Un ejemplo de este tipo de acuerdos entre CCAA y agentes sociales fue el Acuerdo (Pacto de Mesa Sectorial) suscrito entre el Sistema Andaluz de Salud (SAS) y las Organizaciones Sindicales². En este acuerdo aparecen claramente definidos los siguientes "perfiles": Enfermera para área de Quirófano, Enfermera para área de Diálisis, Enfermera para área de Neonatología (Urgencias pediátricas, cuidados críticos neonatales y cuidados críticos pediátricos), Enfermera para área de Cuidados Críticos y Urgencias, Enfermera para área de Salud Mental. Resulta curioso, por no decir perverso, que con los impuestos de todos los españoles se estén formando especialistas a nivel nacional en 2 de estas áreas (Pediatría y Salud Mental) vía EIR, y los diferentes sistemas sanitarios de las CCAA no los contraten como lo que son: Enfermeros Especialistas.

Siguiendo con la lectura de este texto, en el mismo se recoge: Para "inscribirse en la Bolsa de empleo temporal de áreas específicas, debe acreditarse experiencia profesional en dicha área por un período igual o superior a seis meses, consecutivos o no. En su defecto, podrán inscribirse en esta bolsa, aquellos aspirantes que acrediten haber recibido y superado formación teórico-práctica en las Áreas Específicas a la que optan". Indicar también que estas bolsas específicas solo se pueden utilizar para contratación de corta duración (periodo inferior a 4 meses).

Este acuerdo vino a resolver en gran medida, los problemas de cobertura de los periodos vacacionales, aunque lógicamente acabó desvirtuado con el tiempo. Poco a poco la bolsa específica de enfermera para el área de Diálisis, se ha ido nutriendo de enfermeras que cumplen los requisitos formativos de la misma, pero sin experiencia profesional ninguna. Lo más curioso, es que tal como se recoge en el párrafo de la resolución, se debe haber superado formación teórico-práctica para estar en estas bolsas específicas. Sin embargo, la realidad conocida en todas las Unidades de 
Diálisis de Andalucía, es que muchas enfermeras o enfermeros que acceden a esta bolsa no tienen formación práctica ninguna, lo cual no es ninguna garantía de seguridad para los pacientes en diálisis.

A esta situación, que ha sido denunciada años tras año por los responsables de enfermería de las unidades de diálisis, se le ha querido poner arreglo con el texto refundido y actualizaciones del Pacto de Mesa Sectorial de Sanidad de 2010 de fecha3. Una de las modificaciones se refiere a las áreas específicas: "Para inscribirse en la Bolsa de empleo temporal de áreas específicas, debe acreditarse experiencia profesional en dicha área por un período igual o superior a seis meses, consecutivos o no. En su defecto, podrán inscribirse en esta bolsa, aquellos aspirantes que acrediten haber recibido y superado formación teórico-práctica en las Áreas Específicas a la que optan y manifiesten tener la capacidad funcional suficiente para el desempeño". Esta última frase, cuya traducción operativa sería: ¿se siente Ud. capacitado para ser responsable de la diálisis de los pacientes que de acuerdo, a la distribución diaria de pacientes, le sean asignados?, pretende resolver que nos encontremos con profesionales que esté inscritos en la bolsa específica pero sin experiencia previa.

Evidentemente, esto no va a resolver el problema. El problema radica en los criterios de admisión de la Formación Teórico-Práctica requerida, que en la mayoría de las ocasiones, se realiza "on line", con lo cual carece totalmente de competencias prácticas y que en todo caso debería tener un componente práctico equivalente a los 6 meses requeridos de experiencia profesional acreditada.

Como reflexiones finales, indicar que los intereses de los 3 principales agentes que intervienen en el proceso sanitario: usuarios, profesionales y administración, nunca serán coincidentes, pero deben prevalecer en primer lugar las de los usuarios del sistema sanitario; porque sin ellos, aunque resulte una obviedad, no habría necesidad de administración ni de profesionales sanitarios. Por tanto aseguremos una asistencia adecuada, de calidad y segura para los pacientes, pero con los profesionales con las competencias adecuadas, reconocidas y acreditadas para ello.

Rodolfo Crespo Montero Director Enfermería Nefrológica

\section{Referencias}

1. Pérez Aparicio, C. Contratación eventual de enfermeras mediante bolsas específicas. Trabajo Fin de Máster; 2011. Universidad de Almería.

2. Resolución de 21 de junio de 2010, de la Dirección General de personal y desarrollo profesional del Servicio Andaluz de Salud, por la que se dispone la aprobación y publicación del texto refundido y actualizaciones del pacto de mesa sectorial de sanidad, suscrito entre la administración sanitaria de Andalucía-SAS y las organizaciones sindicales -SATSE, CC.00., UGT, CSI-CSIF, SMA Y USAE-, el 18 de mayo de 2010, sobre sistema de selección de personal estatutario temporal para puestos básicos en el Servicio Andaluz de Salud.

3. Resolución de 24 de noviembre de 2015, de la Dirección General de Profesionales del Servicio Andaluz de Salud, de modificación de la Resolución de 21 de junio de 2010, por la que se dispone la aprobación y publicación del texto refundido y actualizaciones del Pacto de Mesa Sectorial de Sanidad suscrito el 18 de mayo de 2010 entre la Administración Sanitaria de Andalucía-SAS y las Organizaciones Sindicales que se citan, sobre sistema de selección de personal estatutario temporal para puestos básicos en el Servicio Andaluz de Salud. 